\title{
Effect of caffeine on delayed-onset muscle soreness: a meta-analysis of RCT
}

\author{
Janisa Andrea Muljadi ${ }^{1}$, Patsorn Kaewphongsri ${ }^{2}$, Kornkit Chaijenkij ${ }^{3}$ and Jatupon Kongtharvonsku ${ }^{4,5^{*}}$
}

\begin{abstract}
Background: There are multiple strategies that have been suggested to attenuate delayed-onset muscle soreness (DOMS). Caffeine has been shown to assist with blocking pain associated with DOMS. However, currently there is still controversy over the effects of caffeine use.

Main body: We conducted a meta-analysis to compare pain associated with muscle soreness by both the VAS and indirect markers by CK of caffeine and placebo after exercise. The meta-analysis was carried out in accordance with the PRISMA guidelines. Relevant studies from Medline and Scopus published up to May 20, 2021, were included, which resulted in a total of 477 and 132 studies being retrieved from Scopus and Medline, respectively. Seven studies met the inclusion criteria, and in these, there were 68 persons in the caffeine group and 74 persons in the placebo group. A visual analog score of muscle soreness was recorded pre-exercise, immediately post-exercise, and at one to four days post-exercise; the scores at these time points in the caffeine group as compared to those in the placebo group progressed from $0.00(95 \% \mathrm{Cl}-0.51,0.50)$ to $-0.20(-1.09,0.69),-0.92(-2.20,0.36),-1.02(-1.86,-0.19)$, $0.00(-0.36,0.36)$, and $0.18(-0.56,0.92)$, respectively. No statistically significant differences were noted for CK between the two groups at $24 \mathrm{~h}$ post-exercise.

Short conclusion: Our meta-analysis results indicate that caffeine supplements reduce delayed-onset muscle soreness when compared to a placebo $48 \mathrm{~h}$ after exercise. However, at $24 \mathrm{~h}$ post-exercise, caffeine can reduce DOMS only in people who worked on resistant exercise. The CK used in this meta-analysis did not show any differences.

Trial registration: PROSPERO CRD42021260248.

Level of evidence I.
\end{abstract}

Keywords: DOMS, Caffeine, Exercise-induced muscle soreness, Meta-analysis

\section{Background}

Delayed-onset muscle soreness (DOMS) normally occurs 1 to 2 days after unaccustomed activity and eccentric muscle contraction, with symptoms including muscle soreness and discomfort (Chen et al. 2019; Connolly et al. 2003). DOMS is normally a symptom of exercise-induced muscle damage (EIMD) (Howatson and Someren 2008). Even among well-trained athletes, high-intensity exercise

\footnotetext{
*Correspondence: Jatupon_kong@hotmail.com

${ }^{4}$ Department of Epidemiology and Biostatistics, Faculty of Medicine, Ramathibodi Hospital, Bangkok, Thailand

Full list of author information is available at the end of the article
}

that involves unaccustomed or eccentric muscle contractions can lead to microscopic intramuscular tears and exaggerated inflammatory responses (Jobin et al. 1999; Shehzad et al. 2011; Jäger et al. 2019). An inflammatory response and the production of reactive oxygen species (ROS) are triggered by this mechanical stress. The reason for this process is that mechanical stress promotes the activation of transcription factors, such as nuclear factor- $\mathrm{kB}$ (NF- $\mathrm{kB}$ ), which limits an athlete's performance and daily activities (Paulsen et al. 2012; GarcíaLópez et al. 2007). EIMD can be manifested by prolonged decline in muscle strength, reduction in range of motion (ROM), swelling, DOMS, and an increase in blood 
muscle proteins and creatine kinase (CK) activity (Warren et al. 1999; Tanabe et al. 2015). Therefore, post-exercise muscle damage should be prevented or minimized.

Caffeine is a stimulant that is widely consumed and has been shown to exhibit many physiological and psychological effects (Astorino and Roberson 2010; Al-Nawaiseh et al. 2020). For many decades, caffeine supplements have been used legally as an ergogenic substance to enhance endurance and attenuate DOMS during exercise under EIMD (Burke 2008). Therefore, athletes use caffeine in order to improve their agility and performance (Astorino and Roberson 2010; Doherty and Smith 2004). The rationale of the increase in performance could be caused by the release of cortisol and beta-endorphins, leading to less exhaustion during physical activities (Costill et al. 1978; Doherty and Smith 2005; Graham 2001; Kalmar and Cafarelli 1999, 2004; Laurent et al. 2000; Tarnopolsky and Cupido 2000). Caffeine has been shown to attenuate DOMS and increase muscle strength and power (Grgic and Pickering 2019; Grgic et al. 2018; Warren et al. 2010) via an enhanced $\mathrm{Ca}^{2+}$ efflux from the sarcoplasmic reticulum (Lamb et al. 2001), a direct $\mathrm{Ca}^{2+}$-sensitizing effect on skeletal muscle (Tallis et al. 2015), and an increase in $\mathrm{Na}^{+}-\mathrm{K}^{+}-$ATPase activity resulting from decreased serum levels of $\mathrm{K}^{+}$(Sökmen et al. 2008). This attenuating effect of caffeine has been shown by clinical studies involving chronic headache, migraine, and postoperative pain (Chen et al. 2019; Sökmen et al. 2008). Although there are many reports of caffeine ingestion attenuating DOMS during exercise under EIMD, the effects of caffeine supplements remain unclear. Several studies reported that caffeine is able to reduce and attenuate delayed-onset muscle soreness (Caldwell et al. 2017; Nobahar 2013; Maridakis et al. 2007). However, others have reported that caffeine is unable to affect DOMS (Chen et al. 2019; Hurley et al. 2013; Al-Nawaiseh et al. 2020; Fogaça et al. 2020). No meta-analysis related to this topic has been published yet. To gain a better understanding of how caffeine supplements affect delayedonset muscle soreness symptoms, we performed a meta-analysis based on the outcomes from studies in the literature.

\section{Main text}

\section{Search strategy and data sources}

This review was conducted according to the transparent reporting of systematic reviews and meta-analyses (PRISMA guideline 2009). The search was performed in the PubMed and Scopus databases, with studies up to May 20, 2021, considered. The following keywords were used as search terms: ((Caffeine) OR (coffee)) AND ((delayed onset muscle soreness) OR (DOMS) OR (Muscle soreness) OR (Muscle pain)). Reference lists of all included studies were screened manually for further eligible articles. The studies were screened independently by two authors (J.M. and P.K.) against the eligibility criteria based on titles and abstracts using the bibliographical software package EndNote version X7. Disagreements were resolved regarding inclusion and exclusion criteria of a study with a third author (J.K.).

\section{Selection criteria}

Studies were included if they met the following criteria: (a) RCT and quasi-RCT studies; (b) reported outcomes based on the muscle soreness index (VAS) or creatine kinase (CK); (c) compared clinical outcomes between a caffeine supplement and placebo; and (d) had adequate data for extraction and pooling. We excluded studies if they used a combination of interventions besides caffeine supplements, and if they were experimental studies using animals, reviews, letters to the editor, or case reports and non-English languages studies.

\section{Data extraction and methodology quality assessment}

The data were extracted from each study through structured data extraction forms by two reviewers (J.M. and P.K.), using data extraction forms. The items extracted were baseline characteristics of the study including average age, sex, study design, mean follow-up time, and caffeine dosage. Clinical outcome data (number of subjects and mean and SD of VAS and CK) between groups were extracted, which was followed by data extraction of frequencies (adverse effects) between treatment groups. When any disagreements in opinion arose, a third author (J.K.) made the final decision. Quality assessment was performed by two authors (J.M. and K.C.) according to the Cochrane Collaboration tool for evaluating the risk of bias in order to avoid the distortion of the meta-analysis outcomes (Higgins et al. 2011). RCT studies were assessed by risk of bias following the PRISMA guideline recommendation (Liberati et al. 2009) based on sequence generation, allocation concealment, blinding, incomplete outcome data, selective outcome reporting, and other sources of bias. Any conflicts between reviewers related to quality assessment were settled by a third reviewer (J.K.).

\section{Outcomes of interest}

The outcomes considered were the VAS of muscle soreness and CK. The measurement of those outcomes was the same as reported in the original studies, namely VAS of muscle soreness $(0-10)$, with lower values equivalent to better outcomes, and $\mathrm{CK}$, with lower values equivalent to better outcomes. 


\section{Statistical methods}

For continuous variables, data were pooled as an unstandardized mean difference (UMD) with 95\% confidence intervals (CI). The heterogeneity across the studies was assessed using the Q statistic and I2 statistic to quantify the degree of heterogeneity. An $\mathrm{I}^{2}$ value of $0 \%$ was considered as no heterogeneity, $25 \%$ as low, $50 \%$ as moderate, and $75 \%$ as high heterogeneity. The statistical significance of heterogeneity was set with a $P$ value of $<0.10$. A random-effect model was used if $\mathrm{I}^{2}>25$; otherwise, a fixed-effect model was applied. In order to explore the cause of heterogeneity, meta-regression was applied in the meta-regression model. According to the results of the meta-regression, sensitivity analyses were performed by leave-one-out to assess the robustness of a pooled conclusion. Funnel plots and an Egger test were used to assess publication bias (Egger et al. 1997; Palmer et al. 2018). The metatrim and fill method was used to estimate the number of studies that might be missing and to adjust the pooled estimate (Duval and Tweedie 2000).
Data were analyzed using STATA version 15.0 (StataCorp. 2017). A $P$ value of $<0.05$ was considered statistically significant, while a $P$ value of $<0.10$ was considered as a threshold of significant heterogeneity.

\section{Results}

A total of 477 AND 132 studies were retrieved from Scopus and Medline, respectively (Fig. 1). Of these, 70 duplicated studies and 532 non-relevant studies were excluded. The remaining seven studies met the inclusion criteria. The characteristics of the seven studies (Chen et al. 2019; Al-Nawaiseh et al. 2020; Caldwell et al. 2017; Nobahar 2013; Maridakis et al. 2007; Hurley et al. 2013; Fogaça et al. 2020) are summarized in Table 1. All studies were RCTs, three had a parallel design and four used a crossover design. Three studies involved resistance exercise, while four studies focused on aerobic exercises. All seven studies reported post-exercise muscle soreness using VAS. An indirect marker of muscle damage was reported using $\mathrm{CK}$ in four of the studies. The mean age

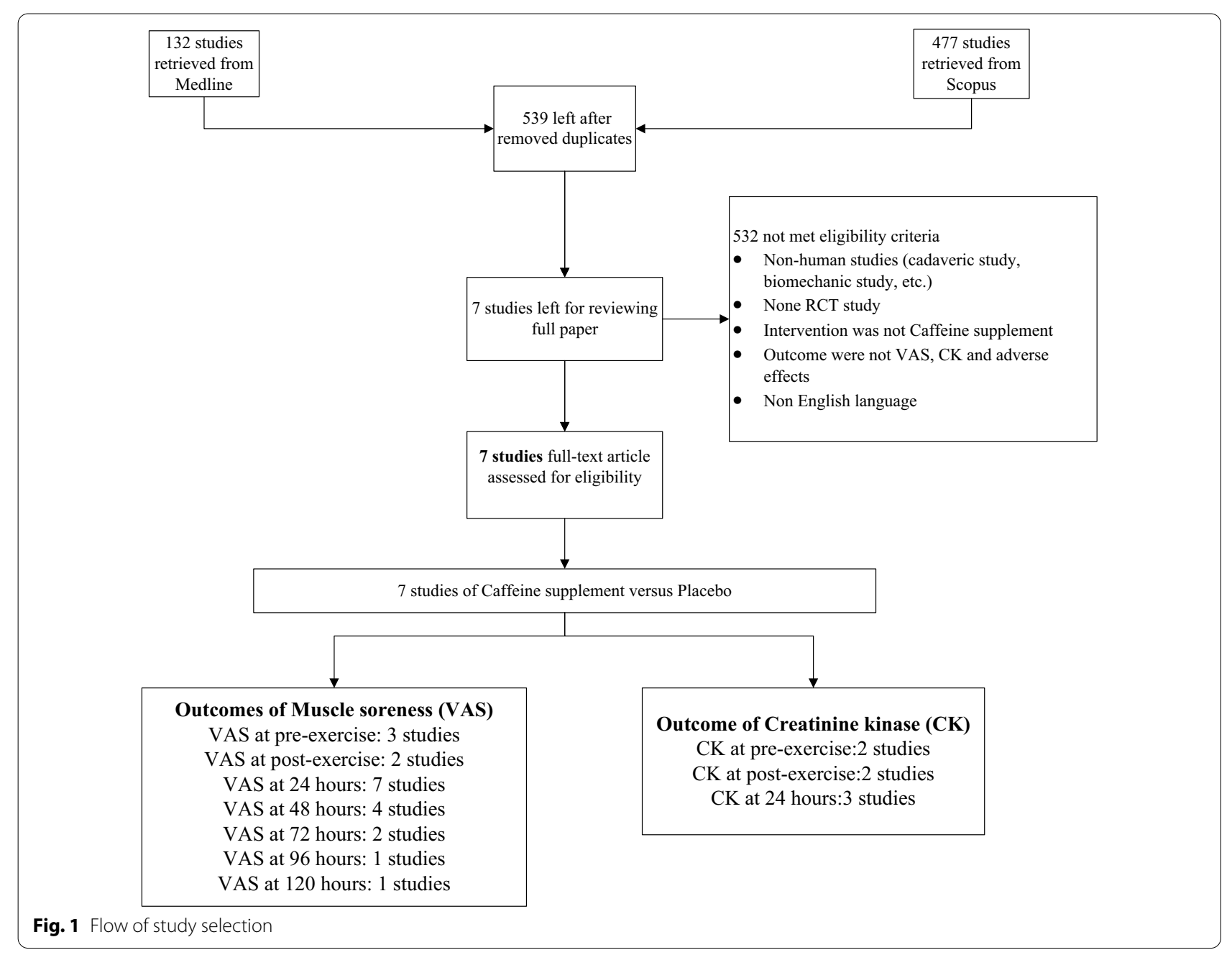


Table 1 Characteristics of included studies

\begin{tabular}{|c|c|c|c|c|c|c|c|c|c|c|c|c|}
\hline Author & Year & Country & $\mathbf{N}$ & $\mathrm{Nc}$ & $\mathrm{Np}$ & $\mathrm{RCT}$ & N (Male \%) & Age (mean) & Outcome & Exercise & $\begin{array}{l}\text { Dose } \\
\text { (mg/ } \\
\text { kg) }\end{array}$ & BMI \\
\hline Chen HY & 2019 & Taiwan & 20 & 10 & 10 & Parallel & 50 & 20.75 & CKVAS & Aerobic & 6 & 21.75 \\
\hline Fogaca LJ & 2020 & Brazil & 9 & 9 & 9 & Crossover & 100 & 28 & CKVAS & Resistance & 6 & 25.5 \\
\hline Hurley CF & 2013 & Rhode Island & 9 & 9 & 9 & Crossover & 100 & 20 & CKVAS & Resistance & 5 & - \\
\hline Al-Nawaiseh AM & 2020 & USA & 11 & 11 & 11 & Crossover & 81.8 & 24.5 & VAS & Aerobic & 5 & 23.18 \\
\hline Maridakis V & 2007 & Georgia & 9 & 9 & 9 & Crossover & 0 & 21.3 & VAS & Resistance & 5 & 20.9 \\
\hline Nobahar M & 2013 & Iran & 16 & 8 & 8 & Parallel & 0 & 22.5 & CKVAS & Aerobic & 1 & - \\
\hline Caldwell AR & 2017 & USA & 30 & 12 & 18 & Parallel & 83.3 & 51.83 & VAS & Aerobic & 3 & - \\
\hline
\end{tabular}

and body mass index (BMI) of participants ranged from 20 to 52 years and from 20.9 to 25.5 , respectively. Two studies reported the proportion of male participants as $0 \%$, while four studies were from 50 to $100 \%$ male. The caffeine dosages used were $1,3,5$, and $6 \mathrm{mg} / \mathrm{kg}$ in $1,1,3$, and 2 studies, respectively.

\section{Risk of bias in included studies}

All seven studies reported with selective and incomplete outcomes, while most used blinding (six out of the seven studies). All studies had unclear sequence generation data and had no allocation of concealment data (Table 2).

\section{Outcomes \\ VAS of muscle soreness pre- and post-exercise at 24, 48, 72, and $96 h$}

The mean difference in VAS of muscle soreness between the caffeine and placebo test groups pre- and post-exercise at 24, 48, 72, and $96 \mathrm{~h}$ is shown in Table 3 and Fig. 2. The pooled UMDs of the caffeine group were -0.00 ( $95 \%$ $\mathrm{CI}-0.51, \quad 0.50),-0.20 \quad(-1.09, \quad 0.69),-0.92 \quad(-2.20$, $0.36),-1.02(-1.86,-0.19),-0.00(-0.36,0.36)$, and $0.18(-0.56,0.92)$ in comparison with those of the placebo group in the pre-exercise period and at $0,24,48$, 72 , and $96 \mathrm{~h}$ post-exercise, respectively. Thus, the mean VAS of muscle soreness differed significantly between the two groups by a score of approximately 1 at $48 \mathrm{~h}$ and borderline significantly by 0.9 at $24 \mathrm{~h}$ (Table 3 and Fig. 2). There were no statistically significant differences between the two groups during the pre-exercise period, and post-exercise after 72 and $96 \mathrm{~h}$. When separately fitting the mean age, gender, study design, mean follow up time, and dose of caffeine supplement at baseline in a meta-regression analysis, only the type of exercise (resistance or aerobic) was able to explain the heterogeneity. Subgroup analysis was performed for the three studies with resistance exercise, and comparing the caffeine and placebo groups showed no heterogeneity $\left(\mathrm{I}^{2}=0 \%\right)$, while in the four studies that used aerobic exercise there was high heterogeneity between the caffeine and placebo groups $\left(\mathrm{I}^{2}=99.5 \%\right)$ (Fig. 3 ). The mean VASs were -1.08 $(95 \% \mathrm{CI}-1.71,-0.45)$ and $-0.89(95 \% \mathrm{CI}-2.59,0.81)$. No evidence of publication bias was suggested by Egger's test and a contour funnel plot (bias $=-2.53, p=0.642$; bias $=4.86, p=0.069$ ).

\section{CK at pre- and post-exercise and $24 \mathrm{~h}$ later}

The mean values of CK between the caffeine and placebo groups in the pre-exercise period and 0 and $24 \mathrm{~h}$ postexercise are shown in Table 4 and Fig. 4. The pooled UMDs were 3.72 (95\% CI-41.84, 49.28), 31.67 (29.50, 33.85), and 49.84 ( $-73.13,172.82) \mathrm{U} / \mathrm{L}$, i.e., the mean CK

Table 2 Risk of bias assessment

\begin{tabular}{|c|c|c|c|c|c|}
\hline Author & Sequence generation & Allocation concealment & Blinding & $\begin{array}{l}\text { Incomplete outcome } \\
\text { data }\end{array}$ & $\begin{array}{l}\text { Selective } \\
\text { outcome } \\
\text { report }\end{array}$ \\
\hline Chen HY & U & $\mathrm{N}$ & Y & Y & Y \\
\hline Fogaca $L J$ & U & $\mathrm{N}$ & Y & Y & Y \\
\hline Hurley CF & U & N & Y & Y & Y \\
\hline Al-Nawaiseh AM & U & $\mathrm{N}$ & Y & Y & Y \\
\hline Maridakis V & U & N & Y & Y & Y \\
\hline Nobahar M & U & $\mathrm{N}$ & U & Y & Y \\
\hline Caldwell AR & U & $\mathrm{N}$ & Y & Y & Y \\
\hline
\end{tabular}


Table 3 VAS

\begin{tabular}{|c|c|c|c|c|c|c|}
\hline \multirow[t]{2}{*}{ Author } & \multicolumn{3}{|l|}{ Caffeine } & \multicolumn{3}{|c|}{ Placebo } \\
\hline & $\mathbf{N}$ & Mean & SD & $\mathbf{N}$ & Mean & SD \\
\hline \multicolumn{7}{|l|}{ A) VAS Pre-exercise } \\
\hline Lorruama J & 9 & 4.7 & 3.67 & 9 & 4.9 & 3.37 \\
\hline Caitlin F & 9 & 0.149 & 0.179 & 9 & 0.298 & 0.417 \\
\hline Maridakis V & 9 & 2.66 & 1.56 & 9 & 1.82 & 1.08 \\
\hline UMD (95\% Cl) & $-0.00(-0.51,0.50)$ & & & & & \\
\hline \multicolumn{7}{|l|}{ B) VAS Post-exercise } \\
\hline Al-Nawaiseh AM & 11 & 3.927 & 2.235 & 11 & 4.009 & 1.956 \\
\hline Maridakis V & 9 & 1.39 & 1.31 & 9 & 1.63 & 0.89 \\
\hline UMD (95\% Cl) & $-0.20(-1.09,0.69)$ & & & & & \\
\hline \multicolumn{7}{|l|}{ C) VAS at $24 h$} \\
\hline Chen $\mathrm{HY}$ & 10 & 0.7525 & 0.1303 & 10 & 0.865 & 0.069 \\
\hline Lorruama J & 9 & 5 & 3.38 & 9 & 5.5 & 3.08 \\
\hline Caitlin F & 9 & 2.59 & 1.25 & 9 & 3.571 & 0.506 \\
\hline Al-Nawaiseh AM & 11 & 5.506 & 1.64 & 11 & 5.022 & 1.38 \\
\hline Maridakis V & 9 & 0.95 & 1.03 & 9 & 2.2 & 1.03 \\
\hline Nobahar M & 8 & 2.5 & 0.175 & 8 & 5 & 0.175 \\
\hline Caldwell AR & 12 & 1.45 & 2.45 & 18 & 2.78 & 1.67 \\
\hline UMD (95\% Cl) & $-0.92(-2.20,0.36)$ & & & & & \\
\hline \multicolumn{7}{|l|}{ D) VAS at $48 \mathrm{~h}$} \\
\hline Caitlin F & 9 & 2.5 & 1.25 & 9 & 4.107 & 0.506 \\
\hline Al-Nawaiseh AM & 11 & 5.3 & 2.204 & 11 & 3.973 & 2.207 \\
\hline Maridakis V & 9 & 0.56 & 1.02 & 9 & 1.81 & 1.01 \\
\hline Caldwell AR & 12 & 0.45 & 0.78 & 18 & 1.78 & 1.33 \\
\hline UMD (95\% Cl) & $-1.02(-1.86,-0.19)$ & & & & & \\
\hline \multicolumn{7}{|l|}{ E) VAS at $72 \mathrm{~h}$} \\
\hline Caitlin F & 9 & 1.369 & 0.476 & 9 & 1.786 & 0.923 \\
\hline Caldwell AR & 12 & 1 & 0.88 & 18 & 1.22 & 1.1 \\
\hline UMD (95\% Cl) & $0.0(-0.36,0.36)$ & & & & & \\
\hline \multicolumn{7}{|l|}{ F) VAS at $96 \mathrm{~h}$} \\
\hline Caitlin F & 9 & 0.952 & 0.774 & 9 & 0.774 & 0.833 \\
\hline UMD (95\% Cl) & $0.18(-0.56,0.96)$ & & & & & \\
\hline
\end{tabular}

difference was approximately $32 \mathrm{U} / \mathrm{L}$, which was a statistically significant difference between the groups in the post-exercise period (Table 4 and Fig. 4). The heterogeneity could not be explained by any of the covariates. No evidence of publication bias was suggested by Egger's test and a contour funnel plot (bias $=1.67, p=0.188$ ).

\section{Analysis in RCT with parallel design}

The UMDs of VAS muscle soreness between caffeine and placebo were -1.31 (95\% CI $-3.27,0.65),-1.33(95 \%$ CI - 2.09, - 0.59), and - 0.22 (95\% CI - 0.22: - 0.93, 0.49) at 24,48 , and $72 \mathrm{~h}$ post-exercise, respectively (Fig. 5 ). The mean VAS muscle soreness between the caffeine and placebo groups differed significantly by approximately 1.3 at $48 \mathrm{~h}$ post-exercise. The differences in the mean values of CK between the caffeine and placebo groups at 0 and 24 h post-exercise were 31.7 (95\% CI 29.49, 33.85) and -15 ( $-16.03,-13.97)$ (Fig. 6). Thus, the mean CK of the caffeine group was statistically significant higher by approximately $32 \mathrm{U} / \mathrm{L}$ immediately post-exercise, while it was statistically significant lower by $15 \mathrm{U} / \mathrm{L}$ at $24 \mathrm{~h}$ postexercise when compared with the placebo group.

\section{Analysis in RCT with crossover design}

The UMDs of VAS muscle soreness between caffeine and placebo were -0.68 (95\% CI $-1.47,0.11),-0.76(95 \%$ $\mathrm{CI}-2.08,0.56)$, and $-0.42(95 \% \mathrm{CI}-1.10,0.26)$ at 24,48 , and $72 \mathrm{~h}$ post-exercise (Fig. 5). There were no significant differences in the mean VAS of muscle soreness between the two groups at 24,48 , and $72 \mathrm{~h}$ post-exercise. The 


\section{VAS preexercise}

Study

ID

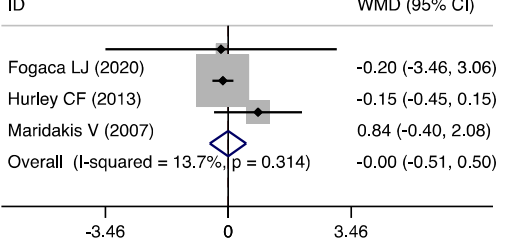

VAS at 48 hours

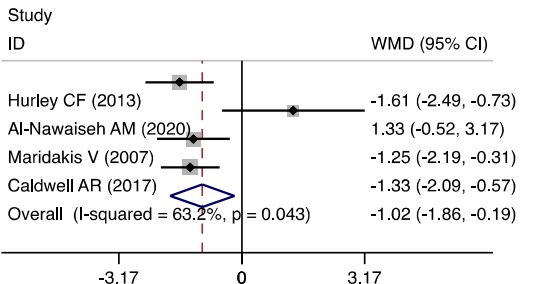

\section{VAS postexercise}

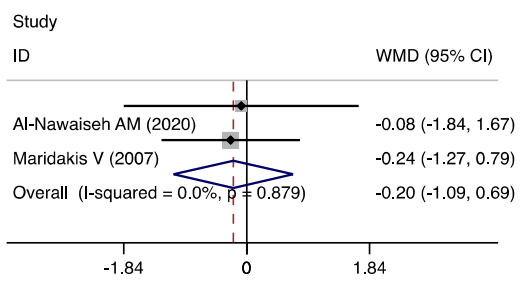

VAS at 72 hours
VAS at 24 hours

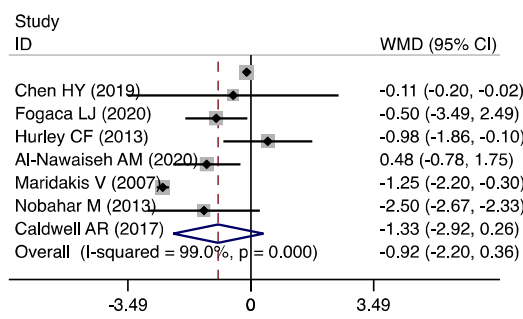

VAS at 96 hours
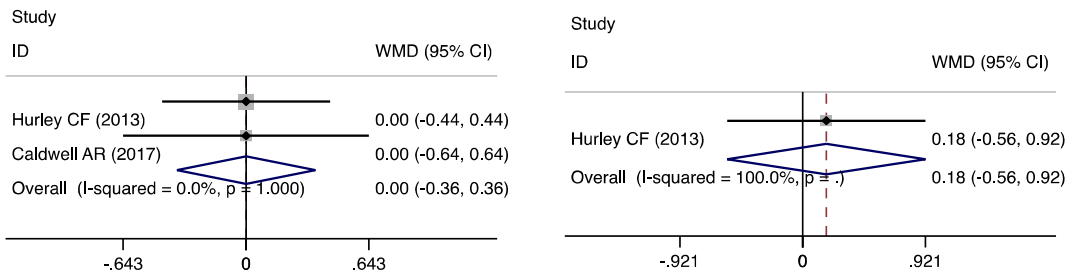

Fig. 2 Forest plot for comparison of VAS at pre, post, 24, 48, 72, and $96 \mathrm{~h}$ after exercise between caffeine supplement versus placebo

\section{Resistance exercise}

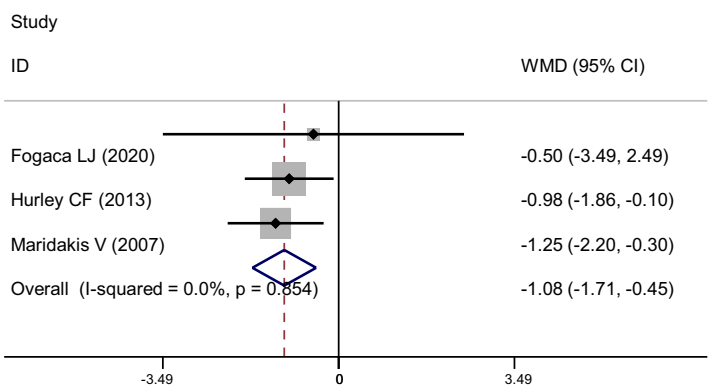

\section{Aerobic exercise}

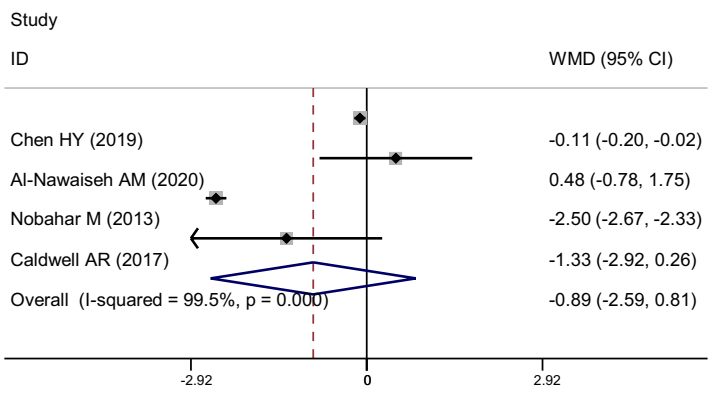

Fig. 3 Forest plot of subgroup analysis of resistance and aerobic exercise for comparison of VAS at $24 \mathrm{~h}$ between two groups

mean CK values for the caffeine and placebo groups at 0 and $24 \mathrm{~h}$ post-exercise were $71(95 \% \mathrm{CI}-197.96,333.96)$ and 170.87 (-124.63, 466.37), respectively (Fig. 6), and this was not a statistically significant difference.

\section{Discussion}

This review indicated that people who took caffeine supplements before and/or after exercise had pain scores about 1 lower than those who took a placebo $48 \mathrm{~h}$ postexercise. For indirect markers of muscle damage, the people who took caffeine supplements before and/or after exercise had higher CK scores by about $32 \mathrm{U} / \mathrm{L}$ than those who took a placebo. However, VASs exhibited no significant difference between the two groups at 24, 72, and $96 \mathrm{~h}$. After performing a subgroup analysis including the type of exercise and RCT design (parallel or crossover), the results showed that patients who had performed resistant exercises with caffeine supplements had significantly lower post-exercise pain VASs at $24 \mathrm{~h}$ than those in the placebo group. Caffeine supplements made no significant difference to VAS pain scores at $24 \mathrm{~h}$ post-exercise in patients who performed aerobic exercise when compared to those in the placebo group. When we used RCT with parallel and crossover in the subgroup analysis, the results of the analysis using RCT with a parallel design were different from the crossover design (Figs. 5 and 6). However, the crossover design may not be appropriate for inclusion in this study, as the repeated bout effect has a significant long-lasting impact in susceptibility to EIMD. Moreover, not being able to control for blinding in 
Table 4 CK

\begin{tabular}{|c|c|c|c|c|c|c|}
\hline \multirow[t]{2}{*}{ Author } & \multicolumn{3}{|l|}{ Caffeine } & \multicolumn{3}{|c|}{ Placebo } \\
\hline & $\mathbf{N}$ & Mean & SD & $\mathbf{N}$ & Mean & SD \\
\hline \multicolumn{7}{|c|}{ A) CKPre-exercise } \\
\hline Lorruama J & 9 & 338.2 & 169.44 & 9 & 293.6 & 124.13 \\
\hline Caitlin F & 9 & 106.183 & 44.355 & 9 & 107.527 & 59.14 \\
\hline Nobahar M & 8 & 83.33 & & 8 & 73.33 & \\
\hline UMD (95\% Cl) & $3.72(-41.84,49.28)$ & & & & & \\
\hline \multicolumn{7}{|c|}{ B) CK Post-exercise } \\
\hline Lorruama J & 9 & 476 & 122.73 & 9 & 405 & 392.96 \\
\hline Nobahar M & 8 & 120 & 2.22 & 8 & 88.33 & 2.22 \\
\hline UMD (95\% Cl) & $31.67(29.50,33.85)$ & & & & & \\
\hline \multicolumn{7}{|l|}{ C) CKat $24 \mathrm{~h}$} \\
\hline Lorruama J & 9 & 1097.6 & 123.45 & 9 & 725.7 & 518.97 \\
\hline Caitlin F & 9 & 211.022 & 111.56 & 9 & 153.226 & 153.226 \\
\hline Nobahar M & 8 & 111.67 & 1.05 & 8 & 126.67 & 1.05 \\
\hline UMD (95\% Cl) & $49.84(-73.13,172.82)$ & & & & & \\
\hline
\end{tabular}

\section{CK preexercise}

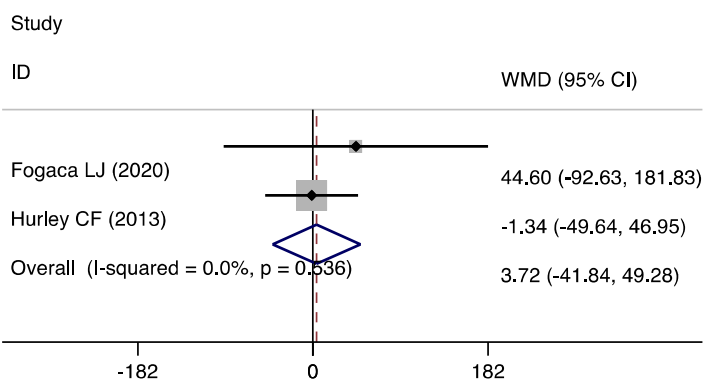

CK at 24 hours

Study

ID

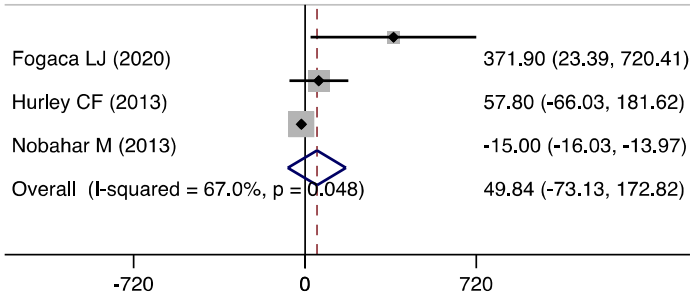

CK postexercise

Study

ID

WMD $(95 \% \mathrm{Cl})$

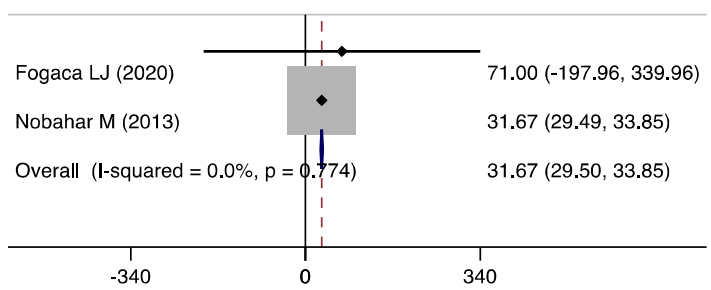

Fig. 4 Forest plot for comparison of CK score at pre and $24 \mathrm{~h}$ after exercise between caffeine supplement versus placebo

a systematic review involving supplementation strategies is a great concern. In this meta-analysis, we included all published studies comparing the effects of caffeine with a placebo because the amount of research that has been published to date is still relatively small. Therefore, we conducted a combined and subgroup analysis and found that the study design did have an effect on the therapeutic use of caffeine.

Caffeine has a greater effect on resistance exercise than aerobic exercise in terms of reducing muscle soreness within $24 \mathrm{~h}$. It is possible that despite inducing muscle soreness, aerobic exercises, such as cycling or 


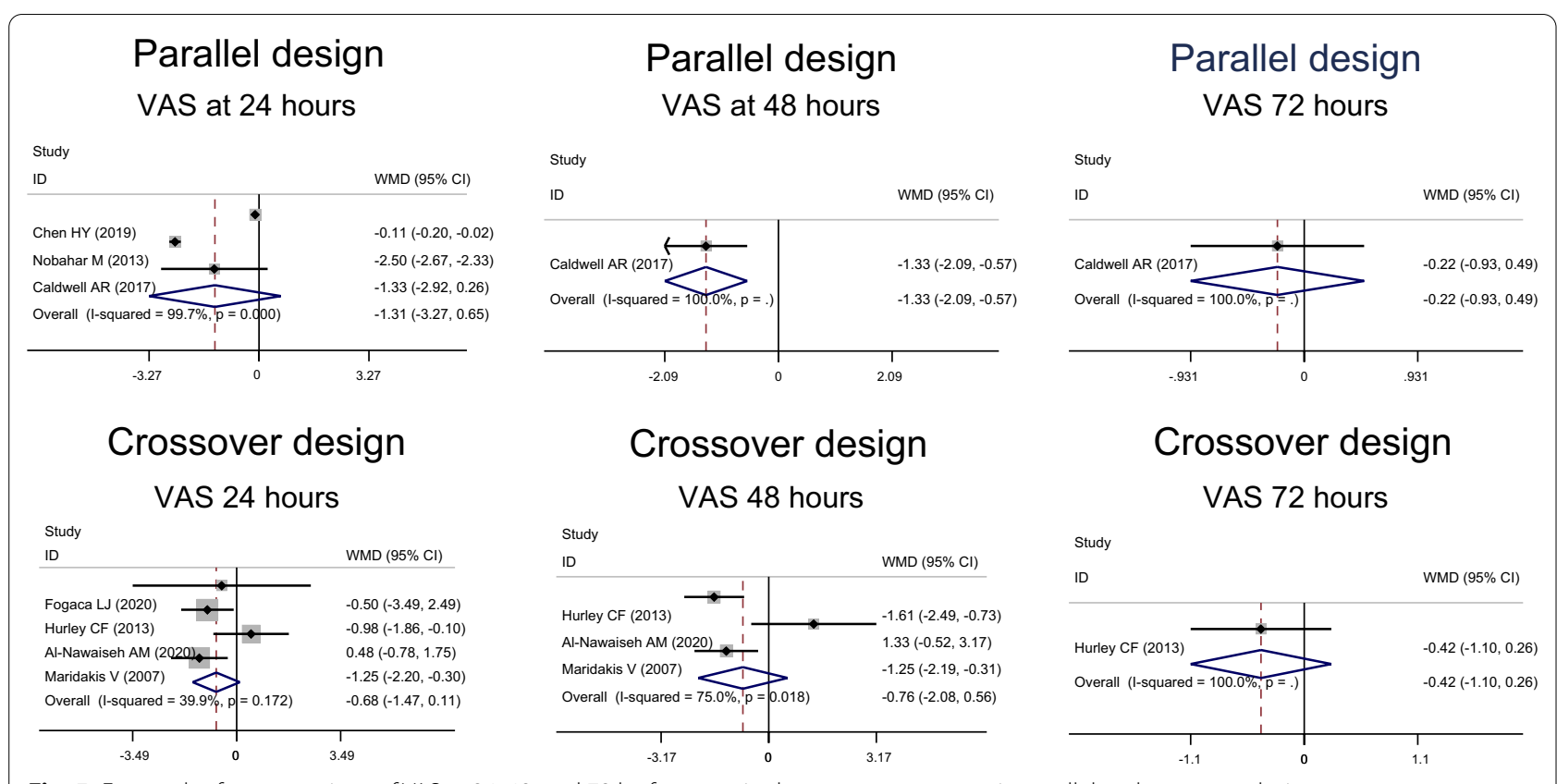

Fig. 5 Forest plot for comparison of VAS at 24, 48, and $72 \mathrm{~h}$ after exercise between two groups in parallel and crossover design

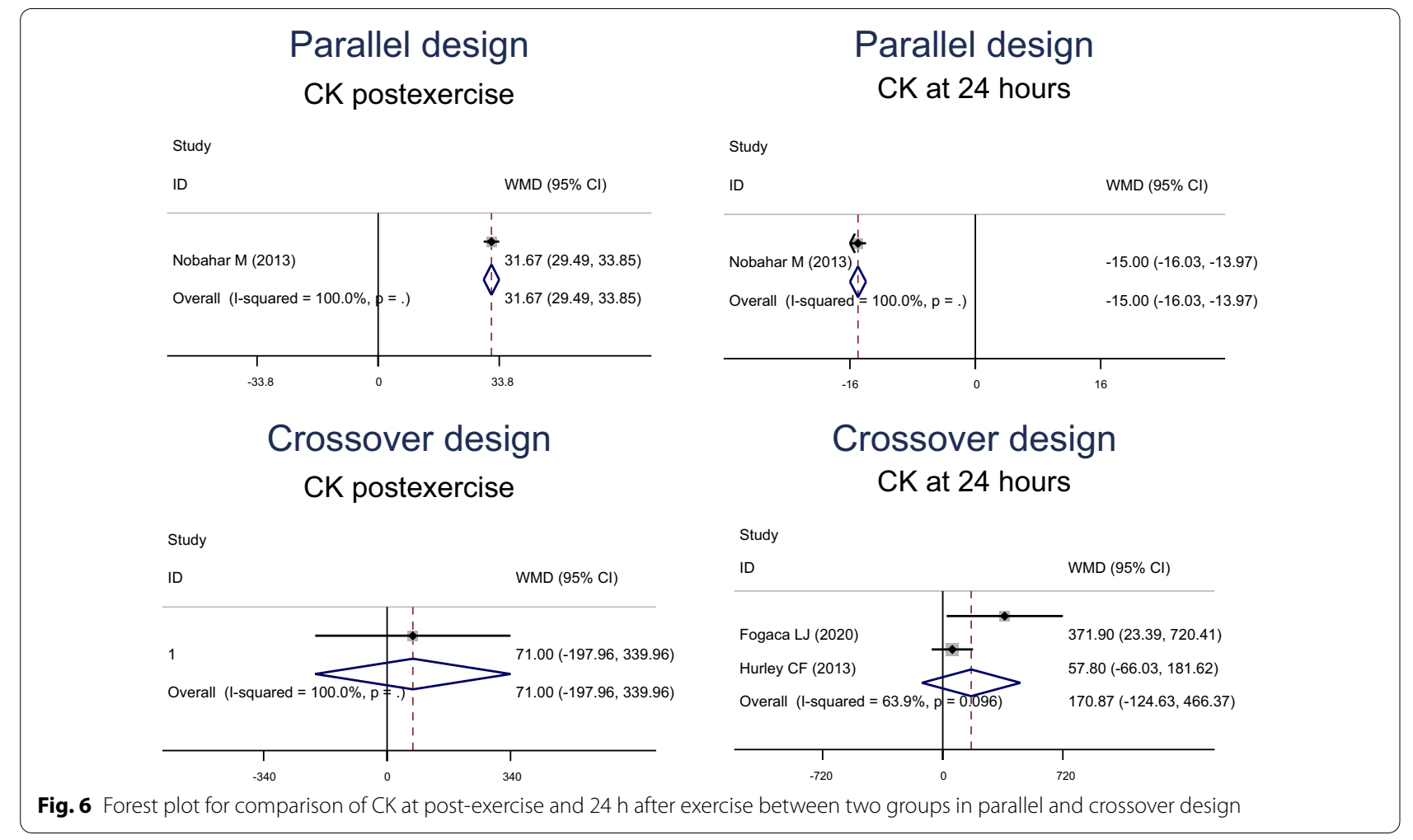

running, which increase the blood flow to the muscles, are better able to remove waste products and deliver nutrients to muscles (Tufano et al. 2012). Therefore, caffeine has no effect on this kind of exercise, but it is effective in reducing muscle pain in people who perform resistance exercise. In the case of both research characteristics (parallel and crossover), there was no effect of caffeine. As the half-life of caffeine in the blood 
stream is about 5 (1.5-9.5) hours, caffeine only stays in the bloodstream for a day (US) 2001). In all crossover studies, seven-day intervals as a washout period were sufficient for the results to be the same as parallel studies.

The precise mechanism for the reduction in pain of caffeine is still uncertain. This is due to the fact that caffeine is a non-selective adenosine receptor antagonist with a high affinity for both $\mathrm{A} 1$ and $\mathrm{A} 2 \mathrm{~A}$ receptors. After 4-8 $\mathrm{h}$ following eccentric exercise, the expression of the gene for the adenosine A1 receptor in human skeletal muscle was increased by almost six times. Furthermore, adenosine A1 receptors have been implicated in the peripheral analgesic effects of adenosine in humans (Chen et al. 2003; Davis et al. 2003; Gaspardone et al. 1995; Motl et al. 2003; Sawynok 1998). Caffeine, which is an adenosine antagonist, has an effect on the activity of the central nervous system (CNS) because the adenosine receptors are blocked. This can result in decreased levels of muscle soreness (Hurley et al. 2013). In previous RCT studies, reduced feelings of pain and fatigue resulting from the adenosine antagonist action of caffeine have been demonstrated (Caldwell et al. 2017; Maridakis et al. 2007; Hurley et al. 2013; Fogaça et al. 2020). This is the first study that describes the reduced perception of soreness at $24-48 \mathrm{~h}$ post-exercise, without a difference in the CK level. Thus, we have found that there is a benefit of ingesting caffeine before the peak of DOMS (caffeine ingested at before exercise and $24 \mathrm{~h}$ after exercise). There were no significant differences in soreness levels between treatments after the third day of follow-up. The caffeine half-life is about $5 \mathrm{~h}$ after intake (Leonard et al. 1987). Therefore, small amounts of caffeine may remain in the body for $24 \mathrm{~h}$. In terms of the CK level, exercises induce CK activity, with levels peaking between 24 and $48 \mathrm{~h}$ after exercise (Brancaccio et al. 2007; Schoenfeld 2012). This delay could be caused by oxidative stress, which is stimulated by lipid peroxidation, and can lead to membrane permeability, allowing muscle constituents such as CK to escape (Owens et al. 2019). In this study, caffeine did not influence CK activity after exercise.

This study has several strengths. First, this was the first meta-analysis that includes seven studies in the pooling of clinical outcomes of tests including caffeine supplement and placebo treatment groups. Second, we explored the possible causes of heterogeneity, when covariate data at baseline were available. Finally, publication bias for each outcome was assessed. However, there are also some limitations to this study. Its scope did not include other important outcomes such as adverse effects, other indirect markers (interleukin and tumor necrotic factor), functional outcomes (range of motion), and the effect of different caffeine levels, since there were incomplete data.
In addition, only English language publications were considered in this study.

\section{Conclusions}

To conclude, caffeine supplements reduce delayed-onset muscle soreness for caffeine supplements compared to a placebo $48 \mathrm{~h}$ after exercise. However, $24 \mathrm{~h}$ after exercise, caffeine may reduce DOMS only in people who have performed resistance exercise. The other marker (CK) used in this meta-analysis did not show any significant differences between the caffeine and placebo treatment groups. Further RCT studies should be performed to assess adverse effects of treatment, other indirect markers (IL and TNF), functional outcomes (range of motion), and the effect of different caffeine levels.

\section{Abbreviations \\ DOMS: Delayed-onset muscle soreness; EIMD: Exercise-induced muscle dam- age; ROS: Reactive oxygen species; NF-kB: Nuclear factor-kB; ROM: Range of motion; CK: Creatine kinase; PRISMA: Preferred Reporting Items for Systematic Reviews and Meta-Analyses; RCTs: Randomized controlled trial studies; VAS: Visual analog score; SD: Standard deviation; UMD: Unstandardized mean dif- ference; BMI: Body mass index; CNS: Central nervous system.}

\section{Acknowledgements}

All authors declare no funding source or sponsor involvement in the study design, collection, analysis and interpretation of the data, in writing the manuscript, and in submission of the manuscript for publication.

\section{Authors' contributions}

$J \mathrm{M}$ was responsible for the conception and design of research, collection of data, analysis and interpretation results of the data, preparing figure, and drafting manuscript. PK was responsible for the collection of research data and assembly of data. KC was responsible for manuscript writing, editing and revising manuscript for important intellectual contents, and final approval of the article. JK was responsible for the conception and design, supervising the analysis and interpretation of data, editing and revising manuscript, critical revision of the manuscript, and approving final version of manuscript and statistical expertise. All authors have read and approved the manuscript.

\section{Funding}

Not applicable.

\section{Availability of data and materials}

All data generated or analyzed during this study are included in this published article.

\section{Declarations}

Ethical approval and consent to participate

Not applicable.

\section{Consent for publication}

Not applicable.

\section{Competing interests}

The authors declare that they have no competing interests.

\section{Author details}

${ }^{1}$ Faculty of Medicine, Ramathibodi Hospital, Bangkok, Thailand. ${ }^{2}$ Mater Dei School, Bangkok, Thailand. ${ }^{3}$ Sports Medicine Center, College of Sports Science and Technology, Mahidol University, Nakhon Pathom, Thailand. ${ }^{4}$ Department of Epidemiology and Biostatistics, Faculty of Medicine, Ramathibodi Hospital, Bangkok, Thailand. ${ }^{5}$ Vejthani Hospital, Bangkok, Thailand. 
Received: 28 June 2021 Accepted: 8 November 2021 Published online: 18 November 2021

\section{References}

Al-Nawaiseh AM, Pritchett RC, Pritchett KK, Bataineh MF, Taifour AM, Bellar D, Schoeff MA, Fox B, Judge A, Judge LW (2020) No significant effect of caffeine on five kilometer running performance after muscle damage. Int J Vitam Nutr Res. https://doi.org/10.1024/0300-9831/a000683

Astorino TA, Roberson DW (2010) Efficacy of acute caffeine ingestion for shortterm high-intensity exercise performance: a systematic review. J Strength Cond Res 24(1):257-265. https://doi.org/10.1519/JSC.0b013e3181c1f88a

Brancaccio P, Maffulli N, Limongelli FM (2007) Creatine kinase monitoring in sport medicine. Br Med Bull 81-82:209-230. https://doi.org/10.1093/ $\mathrm{bmb} / \mathrm{ldm} 014$

Burke LM (2008) Caffeine and sports performance. Int J Vitam Nutr Res 33(6):1319-1334. https://doi.org/10.1139/h08-130

Caldwell AR, Tucker MA, Butts CL, McDermott BP, Vingren JL, Kunces LJ, Lee EC, Munoz CX, Williamson KH, Armstrong LE, Ganio MS (2017) Effect of caffeine on perceived soreness and functionality following an endurance cycling event. J Strength Cond Res 31(3):638-643. https://doi.org/10. 1519/jsc.0000000000001608

Chen YW, Hubal MJ, Hoffman EP, Thompson PD, Clarkson PM (2003) Molecular responses of human muscle to eccentric exercise. J Appl Physiol 95(6):2485-2494. https://doi.org/10.1152/japplphysiol.01161.2002

Chen HY, Chen YC, Tung K, Chao HH, Wang HS (2019a) Effects of caffeine and sex on muscle performance and delayed-onset muscle soreness after exercise-induced muscle damage: a double-blind randomized trial. J Appl Physiol 127(3):798-805. https://doi.org/10.1152/japplphysiol.01108. 2018

Connolly DA, Sayers SP, McHugh MP (2003) Treatment and prevention of delayed onset muscle soreness. J Strength Cond Res 17(1):197-208. https://doi.org/10.1519/1533-4287(2003)017\%3c0197:tapodo\%3e2.0.co;2

Costill DL, Dalsky GP, Fink WJ (1978) Effects of caffeine ingestion on metabolism and exercise performance. Med Sci Sports 10(3):155-158

Davis JM, Zhao Z, Stock HS, Mehl KA, Buggy J, Hand GA (2003) Central nervous system effects of caffeine and adenosine on fatigue. Am J Physiol Regul Integr Comp Physiol 284(2):R399-404. https://doi.org/10.1152/ajpregu. 00386.2002

Doherty M, Smith PM (2004) Effects of caffeine ingestion on exercise testing: a meta-analysis. Int J Sport Nutr Exerc Metab 14(6):626-646. https://doi. org/10.1123/ijsnem.14.6.626

Doherty M, Smith PM (2005) Effects of caffeine ingestion on rating of perceived exertion during and after exercise: a meta-analysis. Scand J Med Sci Sports 15(2):69-78. https://doi.org/10.1111/j.1600-0838.2005.00445.x

Duval S, Tweedie R (2000) Trim and fill: A simple funnel-plot-based method of testing and adjusting for publication bias in meta-analysis. Biometrics 56(2):455-463

Egger M, Davey Smith G, Schneider M, Minder C (1997) Bias in meta-analysis detected by a simple, graphical test. BMJ 315(7109):629-634

Fogaça LJ, Santos SL, Soares RC, Gentil P, Naves JP, Dos Santos WD, Pimentel GD, Bottaro M, Mota JF (2020) Effect of caffeine supplementation on exercise performance, power, markers of muscle damage, and perceived exertion in trained CrossFit men: a randomized, double-blind, placebocontrolled crossover trial. J Sports Med Phys Fitness 60(2):181-188. https://doi.org/10.23736/s0022-4707.19.10043-6

García-López D, Cuevas MJ, Almar M, Lima E, De Paz JA, González-Gallego J (2007) Effects of eccentric exercise on NF-kappaB activation in blood mononuclear cells. Med Sci Sports Exerc 39(4):653-664. https://doi.org/ $10.1249 /$ mss.0b013e31802f04f6

Gaspardone A, Crea F, Tomai F, Versaci F, lamele M, Gioffrè G, Chiariello L, Gioffrè PA (1995) Muscular and cardiac adenosine-induced pain is mediated by A1 receptors. J Am Coll Cardiol 25(1):251-257. https://doi.org/10.1016/ 0735-1097(94)00352-q

Graham TE (2001) Caffeine and exercise: metabolism, endurance and performance. Sports Med 31(11):785-807. https://doi.org/10.2165/00007256200131110-00002

Grgic J, Pickering C (2019) The effects of caffeine ingestion on isokinetic muscular strength: A meta-analysis. J Sci Med Sport 22(3):353-360. https:// doi.org/10.1016/j.jsams.2018.08.016
Grgic J, Trexler ET, Lazinica B, Pedisic Z (2018) Effects of caffeine intake on muscle strength and power: a systematic review and meta-analysis. J Int Soc Sports Nutr 15:11. https://doi.org/10.1186/s12970-018-0216-0

Higgins JP, Altman DG, Gøtzsche PC, Jüni P, Moher D, Oxman AD, Savovic J, Schulz KF, Weeks L, Sterne JA (2011) The Cochrane Collaboration's tool for assessing risk of bias in randomised trials. BMJ 343:d5928. https://doi.org/ 10.1136/bmj.d5928

Howatson G, van Someren KA (2008) The prevention and treatment of exercise-induced muscle damage. Sports Med 38(6):483-503. https://doi. org/10.2165/00007256-200838060-00004

Hurley CF, Hatfield DL, Riebe DA (2013) The effect of caffeine ingestion on delayed onset muscle soreness. J Strength Cond Res 27(11):3101-3109. https://doi.org/10.1519/JSC.0b013e3182a99477

Jäger R, Purpura M, Kerksick CM (2019) Eight weeks of a high dose of curcumin supplementation may attenuate performance decrements following muscle-damaging exercise. Nutrients 11(7):1692. https://doi.org/10.3390/ nu11071692

Jobin C, Bradham CA, Russo MP, Juma B, Narula AS, Brenner DA, Sartor RB (1999) Curcumin blocks cytokine-mediated NF-kappa B activation and proinflammatory gene expression by inhibiting inhibitory factor I-kappa B kinase activity. J Immunol 163(6):3474-3483

Kalmar JM, Cafarelli E (1999) Effects of caffeine on neuromuscular function. J Appl Physiol 87(2):801-808. https://doi.org/10.1152/jappl.1999.87.2.801

Kalmar JM, Cafarelli E (2004) Caffeine: a valuable tool to study central fatigue in humans? Exerc Sport Sci Rev 32(4):143-147. https://doi.org/10.1097/ 00003677-200410000-00004

Lamb GD, Cellini MA, Stephenson DG (2001) Different Ca2+ releasing action of caffeine and depolarisation in skeletal muscle fibres of the rat. J Physiol 531(Pt 3):715-728. https://doi.org/10.1111/j.1469-7793.2001.0715h.x

Laurent D, Schneider KE, Prusaczyk WK, Franklin C, Vogel SM, Krssak M, Petersen KF, Goforth HW, Shulman GI (2000) Effects of caffeine on muscle glycogen utilization and the neuroendocrine axis during exercise. J Clin Endocrinol Metab 85(6):2170-2175. https://doi.org/10.1210/jcem.85.6. 6655

Leonard TK, Watson RR, Mohs ME (1987) The effects of caffeine on various body systems: a review. J Am Diet Assoc 87(8):1048-1053

Liberati A, Altman DG, Tetzlaff J, Mulrow C, Gotzsche PC, loannidis JP, Clarke M, Devereaux PJ, Kleijnen J, Moher D (2009) The PRISMA statement for reporting systematic reviews and meta-analyses of studies that evaluate health care interventions: explanation and elaboration. PLoS Med 6(7):e1000100

Maridakis V, O'Connor PJ, Dudley GA, McCully KK (2007) Caffeine attenuates delayed-onset muscle pain and force loss following eccentric exercise. J Pain 8(3):237-243. https://doi.org/10.1016/j.jpain.2006.08.006

Motl RW, O'Connor PJ, Dishman RK (2003) Effect of caffeine on perceptions of leg muscle pain during moderate intensity cycling exercise. J Pain 4(6):316-321. https://doi.org/10.1016/s1526-5900(03)00635-7

Nobahar M (2013) Effect of caffeine consumption and aerobic exercise on delayed onset muscle soreness. Adv Environ Biol 7(11):3440-3443

Owens DJ, Twist C, Cobley JN, Howatson G (2019) Exercise-induced muscle damage: what is it, what causes it and what are the nutritional solutions? Eur J Sport Sci 19(1):71-85. https://doi.org/10.1080/17461391.2018.15059 57

Palmer TM, Peter JL, Sutton AJ (2018) Moreno SG Contour-enhanced funnel plots for meta-analysis. STATA J 8(2):242-254

Paulsen G, Mikkelsen UR, Raastad T, Peake JM (2012) Leucocytes, cytokines and satellite cells: what role do they play in muscle damage and regeneration following eccentric exercise? Exerc Immunol Rev 18:42-97

Sawynok J (1998) Adenosine receptor activation and nociception. Eur J Pharmacol 347(1):1-11. https://doi.org/10.1016/s0014-2999(97)01605-1

Schoenfeld BJ (2012) Does exercise-induced muscle damage play a role in skeletal muscle hypertrophy? J Strength Cond Res 26(5):1441-1453. https://doi.org/10.1519/JSC.0b013e31824f207e

Shehzad A, Ha T, Subhan F, Lee YS (2011) New mechanisms and the anti-inflammatory role of curcumin in obesity and obesity-related metabolic diseases. Eur J Nutr 50(3):151-161. https://doi.org/10.1007/ s00394-011-0188-1

Sökmen B, Armstrong LE, Kraemer WJ, Casa DJ, Dias JC, Judelson DA, Maresh CM (2008) Caffeine use in sports: considerations for the athlete. J Strength Cond Res 22(3):978-986. https://doi.org/10.1519/JSC.0b013 e3181660cec 
StataCorp (2017) Stata Statistical Software: Release 15. StataCorp LLC, College Station, TX

Tallis J, Duncan MJ, James RS (2015) What can isolated skeletal muscle experiments tell us about the effects of caffeine on exercise performance? $\mathrm{Br} J$ Pharmacol 172(15):3703-3713. https://doi.org/10.1111/bph.13187

Tanabe Y, Maeda S, Akazawa N, Zempo-Miyaki A, Choi Y, Ra SG, Imaizumi A, Otsuka Y, Nosaka K (2015) Attenuation of indirect markers of eccentric exercise-induced muscle damage by curcumin. Eur J Appl Physiol 115(9):1949-1957. https://doi.org/10.1007/s00421-015-3170-4

Tarnopolsky M, Cupido C (2000) Caffeine potentiates low frequency skeletal muscle force in habitual and nonhabitual caffeine consumers. J Appl Physiol 89(5):1719-1724. https://doi.org/10.1152/jappl.2000.89.5.1719 Tufano JJ, Brown LE, Coburn JW, Tsang KK, Cazas VL, LaPorta JW (2012) Effect of aerobic recovery intensity on delayed-onset muscle soreness and strength. J Strength Cond Res 26(10):2777-2782. https://doi.org/10.1519/ JSC.0b013e3182651c06

(US); 2001. 2, Pharmacology of Caffeine. Available from: https://www.ncbi.nlm. nih.gov/books/NBK223808/loMUCoMNRCftSoMTPFfMOWDNAP.

Warren GL, Lowe DA, Armstrong RB (1999) Measurement tools used in the study of eccentric contraction-induced injury. Sports Med 27(1):43-59. https://doi.org/10.2165/00007256-199927010-00004

Warren GL, Park ND, Maresca RD, McKibans KI, Millard-Stafford ML (2010) Effect of caffeine ingestion on muscular strength and endurance: a metaanalysis. Med Sci Sports Exerc 42(7):1375-1387. https://doi.org/10.1249/ MSS.0b013e3181cabbd8

\section{Publisher's Note}

Springer Nature remains neutral with regard to jurisdictional claims in published maps and institutional affiliations.

\section{Submit your manuscript to a SpringerOpen ${ }^{\circ}$ journal and benefit from:}

- Convenient online submission

- Rigorous peer review

- Open access: articles freely available online

- High visibility within the field

- Retaining the copyright to your article

Submit your next manuscript at $\boldsymbol{\nabla}$ springeropen.com 